\title{
An Observational Study on Use of Intravenous Paracetamol for Closure of Patent Ductus Arteriosus in Newborns
}

\author{
Diwas Dhungana', Manish Shrestha' ${ }^{2}$, Suchita Joshi' \\ 'Department of Neonatology, Nepal Mediciti Hospital, Lalitpur, Nepal \\ ${ }^{2}$ Department of Paediatric cardiology, Nepal Mediciti Hospital, Lalitpur, Nepal
}

\begin{abstract}
INTRODUCTION

Failure or delay in spontaneous closure of ductus arteriosus is commonly seen among very low birth weight and very preterm neonates (<32 weeks), results in patent ductus arteriosus (PDA). Hemodynamically significant PDA (hs-PDA) is associated with significant morbidity and mortality if not timely intervened. At present, treatment modalities for hsPDA remain pharmacological with nonspecific cyclo-oxygenase inhibitors such as ibuprofen/indomethacin or surgical ligation whenever pharmacological management is contraindicated. Recently, trials with prostaglandin synthase inhibitor, paracetamol are emerging as an effective treatment modality for PDA closure. In this retrospective observational cohort study, we evaluated the effectiveness of intravenous paracetamol as a first line therapy in very low birth weight infants with hemodynamically significant PDA.
\end{abstract}

\section{METHODS}

Twenty four preterm infants with hemodynamically significant PDA (hs-PDA) were treated with intravenous paracetamol $15 \mathrm{mg} / \mathrm{kg}$ every 6 hourly and subsequent closure was evaluated clinically and by follow-up 2D-Echocardiography. The dosage of $15 \mathrm{mg} / \mathrm{kg}$ for IV paracetamol was chosen based on previously reported data for paracetamol in the treatment of PDA in preterm newborns 1

\section{RESULTS}

PDA closure following intravenous paracetamol was evident in 22 preterm neonates (91.67\%). There were no significant side effects noted with paracetamol therapy.

\section{CONCLUSIONS}

This study concludes that intravenous paracetamol is an effective alternative for the pharmacological closure of hemodynamically significant patent ductus arteriosus in preterm infants.

\section{KEYWORDS}

Paracetamol; Preterm infants; Patent ductus arteriosus.

\section{INTRODUCTION}

Ductus arteriosus is a vascular connection between the descending aorta and pulmonary artery at its bifurcation. During foetal life, most of the pulmonary arterial oxygenated blood is shunted through the ductus arteriosus into the aorta. After birth, the functional closure of ductus arteriosus ensues within 48 hours in full term neonates. ${ }^{2}$ A patent ductus arteriosus (PDA) up to the third day of life is a physiological shunt in healthy term and preterm infants. However failure to close the ductus arteriosus results in pathological condition. Hemodynamically significant PDA (hs-PDA) is a common complication for very preterm infants with high morbidity and mortality, affecting more than $40 \%$ of preterm infants.3The incidence of PDA is inversely related to birth weight and gestational age (GA). ${ }^{4}$
Recent studies have shown that paracetamol can be used as an alternative to treat PDA in preterm infants with good efficacy and less side effects. ${ }^{5}$ Rationale of the study is that intravenous paracetamol is easily available in Nepal. It is cheap, is known to have fewer side effects than either ibuprofen or indomethacin and can be used in infants where use of ibuprofen and indomethacin are contraindicated. Most importantly, intravenous ibuprofen and indomethacin are not readily available in our country whereas intravenous paracetamol is readily available at an affordable price, and hence it could potentially be a promising option for management of hs-PDA in preterm infants in Nepal.

\footnotetext{
*Corresponding Author | Dr Diwas Dhungana

Department of Neonatology, Nepal Mediciti Hospital, Bhaisepati-18, Lalitpur, Nepal Tel: +977-9849848785 | Email: diwas3@gmail.com
} 
The aim of this study was to present our experience with intravenous paracetamol as a first line pharmacological therapy on closure of hs-PDA in preterm neonates.

\section{METHODS}

Study design: A retrospective observational cohort study was conducted in a Level III NICU in Nepal Mediciti hospital. Records of all preterm neonates admitted in the NICU were reviewed and those born at gestational age $\leq 32$ weeks and admitted within 72 hours of age were included in the study.

Study place and duration: Department of neonatology, Neonatal intensive care unit, Nepal Mediciti Hospital, Nepal from November 2017 till January 2020 AD.

Ethical approval and Patient consent: Ethical approval was taken from the hospital institutional review committee. Patient consent is not relevant since the cases were evaluated retrospectively from the past case notes, medical records and NICU database.

\section{Inclusion criteria:}

- Gestational age <32 weeks at birth and admitted within 72 hours of age

- Hemodynamically significant PDA is defined as size $\geq 1.5$ $\mathrm{mm}$; a left atrium to aortic root ratio $>1.5$, and diastolic aortic retrograde flow (diagnosed by 2D echocardiography within the first 72 hours of life)

\section{Exclusion criteria}

- PDA associated with other congenital heart disease.

- Infants who failed to have echocardiography within the first 72 hours after birth.

Sample size determination: All patients born between November 2017 and January 2020 who fulfilled the inclusion criteria were included.

Procedure: Preterm neonates diagnosed clinically and by $2 \mathrm{D}$ echocardiography within 72 hours of life with hemodynamically significant PDA were included in the study. Intravenous paracetamol @15mg/kg/dose every 6 hourly were started and continued for 72 hours till 7 days until subsequent closure of PDA was achieved, which was evaluated clinically and with follow up 2D echocardiography. PDA closure was considered early when treatment was required for less than 72 hours. Similarly PDA requiring treatment for more than 72 hours until 7 days was considered late closure. Those failing to close despite medical treatment for 7 days was considered failure of medical management and surgical closure were performed .These data were analysed to determine if intravenous paracetamol was effective in closing hs-PDA in preterm neonates.
Significance of the study: The use of intravenous paracetamol is evolving as a new therapy for the closure of hs-PDA. If it is so, then the management of preterm neonates with hsPDA will be achieved easily without surgical intervention and with lesser complications as compared to other nonsteroidal anti inflammatory agents.

Statistical analysis: The data were analysed using SPSS 20 software.

\section{RESULTS}

In the study period (November 2017 - January 2020), a total of 631 newborn were admitted in NICU. Out of those, 100 were preterm newborns $\leq 32$ weeks gestations. $24 / 100$ cases were identified as having a hemodynamically significant PDA and met the inclusion criteria. One case was excluded due to PDA associated with congenital heart disease (Dextrocardia with partial atrio-ventricular septal defect and moderate pulmonary artery hypertension). Average gestational age was 28 weeks, average birth weight was 1255 grams and average Apgar score were 6 and 7 at 1 and 5 minutes respectively. All 24 neonates with hs-PDA were treated with intravenous paracetamol @15mg/kg/dose every 6 hourly and continued for minimum of 72 hours and a maximum of 7 days. The result was evaluated clinically and with follow up 2D echocardiography. 22 (91.67\%) preterm newborns achieved complete closure of PDA within 7 days of treatment. Out of 22 successfully closed PDA, $14(63.6 \%)$ cases achieved complete closure within 72 hours of paracetamol therapy whereas in remaining $8(36.4 \%)$ cases, closure was achieved within 7 days of treatment with intravenous paracetamol. There were no significant side effects noted with paracetamol therapy. Two (8.33\%) cases failed to achieve the pharmacological closure of PDA and surgical ligation was performed (Table 1).

Table No 1. Duration of treatment with IV Paracetamol for

PDA closure

\begin{tabular}{|c|c|c|c|}
\hline \multirow[t]{2}{*}{$\begin{array}{l}\text { No of cases } \\
\text { (n) }\end{array}$} & \multicolumn{2}{|c|}{$\begin{array}{l}\text { Closure achieved within } 7 \text { days } \\
(n=22) \%\end{array}$} & $\begin{array}{l}\text { Surgical } \\
\text { ligation }\end{array}$ \\
\hline & $\begin{array}{l}\text { Closure within } \\
72 \text { hours of } \\
\text { treatment, n (\%) }\end{array}$ & $\begin{array}{l}\text { Closure } \\
\text { requiring } \\
\text { more than } 72 \\
\text { hours, n (\%) }\end{array}$ & $\begin{array}{l}\text { (Non closure } \\
\text { despite } \\
7 \text { days of } \\
\text { treatment), } \\
\text { n (\%) }\end{array}$ \\
\hline $24(100.0)$ & $14(63.6)$ & $8(36.4)$ & $2(8.3)$ \\
\hline Total $(n=24)$ & \multicolumn{2}{|l|}{$22(91.67)$} & $2(8.33)$ \\
\hline
\end{tabular}


Although surgical ligation was a success, one preterm died due to sepsis and other due to withdrawal of ventilator support. In remaining 22 cases, PDA closure was ensured. Although improvement was noted, 6 preterm newborns later succumbed to grave conditions not associated with PDA. Three cases had intraventricular haemorrhage grade III and sepsis, two had pulmonary haemorrhage and one died due to fulminant sepsis.

\section{DISCUSSION}

Therapeutic approach for the management of hemodynamically significant PDA in preterm newborns has been a challenge to the neonatologists and paediatric cardiologists. Potential morbidity associated with PDA requires prompt management. First line treatment drugs (indomethacin and ibuprofen) have well established side effects which lead us to alternative treatment options for PDA management. This study demonstrates the efficacy of paracetamol as a first line pharmacological approach in treating preterm neonates with hs-PDA.

Hammerman et al. reported the first case series of successful treatment of hs-PDA with paracetamol in 2011. Since then multiple case studies have been published. ${ }^{5}$

Memisoglu et al 2015 conducted a case series of neonates with hs-PDA treated with paracetamol due to contraindications to ibuprofen and indomethacin. Successful PDA closure was achieved in 90.9\% of the cases with no adverse reactions which was similar to our result where we had $91.7 \%$ closure rate. ${ }^{6}$

Le $\mathrm{J}$ et al conducted an analysis in 2015 which included 2 randomised controlled trials and 12 case series. More than $76 \%$ of the cases received complete PDA closure in case series and reported PDA closure rates with paracetamol in RCTs ranged from 72.5 to $81.2 \%$ with few incidences of elevated liver enzymes.7 A systematic review and metaanalysis conducted by Yingqi Xiao in 2020 concluded that paracetamol induces early patent ductus arteriosus closure without significant side effects. ${ }^{8}$ The result of the meta analysis was similar to our result which had no short term side effects whatsoever during the course of treatment.

In 2016 a study was conducted by Valerio E et al. in which paracetamol therapy was given for PDA closure as a first line therapy when ibuprofen was contraindicated and for rescue therapy for ibuprofen failure. The overall PDA closure rates being, respectively, 56.7 and $61.1 \%$ after two cycles and 63.3 and $77.8 \%$ after three cycles. No toxicity was apparent after either "first-line" or "rescue" paracetamol treatment. On multivariate analysis, gestational age (GA) emerged as an independent predictor of PDA closure in the "first-line" paracetamol treatment group, while clinical risk index for babies (CRIB) score was an independent predictor of PDA closure failure in the "rescue" group (Table 2). ${ }^{9}$

Table No 2. The association between gender, gestational age, birth weight in closure of PDA in preterm neonates.

\begin{tabular}{|l|l|l|l|}
\hline \multicolumn{2}{|l|}{} & $\begin{array}{l}\text { Response to } \\
\text { PCM }\end{array}$ & $\begin{array}{l}\text { No response } \\
\text { to PCM }\end{array}$ \\
& Male & $13(92.9 \%)$ & $1(7.1 \%)$ \\
\cline { 2 - 4 } & Female & $9(90 \%)$ & $1(10 \%)$ \\
\hline \multirow{4}{*}{ Gender } & $<28$ & $4(80 \%)$ & $1(20 \%)$ \\
\hline \multirow{5}{*}{ Gestational age (week) } & $28-30$ & $16(94.1 \%)$ & $1(5.9 \%)$ \\
\cline { 2 - 4 } & $31-32$ & $2(100 \%)$ & $0(0 \%)$ \\
\hline \multirow{3}{*}{ Level of CRIB } & $<1000$ & $3(100 \%)$ & $0(0 \%)$ \\
\cline { 2 - 4 } & $1000-1500$ & $16(88.9 \%)$ & $2(11.1 \%)$ \\
\cline { 2 - 4 } & $>1500$ & $3(100 \%)$ & $0(0 \%)$ \\
\hline & 1 & $9(100 \%)$ & $0(0 \%)$ \\
\cline { 2 - 4 } & 2 & $11(91.7 \%)$ & $1(8.3 \%)$ \\
\cline { 2 - 4 } & 3 & $2(66.7 \%)$ & $1(33.3 \%)$ \\
\hline
\end{tabular}

Tofel et al. in 2018 have reported $77.7 \%$ successful closure of PDA with i.v paracetamol with significant rise in transaminases in 2/9 cases not requiring any treatment for normalization. ${ }^{10}$ Another study conducted by Sunil B et al. in 2018 with i.v. paracetamol for PDA closure resulted in $75 \%$ successful closure with no significant side effects. ${ }^{11}$

Guimaraes AF et al., in 2019 evaluated the efficacy of paracetamol therapy in inducing ductal closure in 87 cases. The overall PDA closure rate after one or two cycles of paracetamol therapy was recorded to be $67(74.7 \%)$. No side effect was observed after the treatment and aminotransferase levels were maintained within reference limits. During the study, it was observed that some preterm newborns needed a longer treatment period to achieve ductal closure, which prompted a readjustment to the protocol, and treatment duration was extended to 7 days. ${ }^{12}$ Another clinical trial by Dash et al., obtained a ductal closure rate of $100 \%$ with a 7 day treatment with paracetamol. ${ }^{13}$ Also El-Khuffash et al., compared long (7 days) to short (2 days) courses of oral paracetamol and obtained a better results with longer duration of treatment.14 Above studies are complementing with our study where we prescribed paracetamol for minimal 3 days to maximum 7 days and achieved a ductal closure of $91.7 \%$.

\section{CONCLUSIONS}

Although our study showed results in favour of intravenous paracetamol as a first line drug for PDA closure in preterm newborns, the major limitations of the present study were that, it is a non-randomized retrospective cohort study 
with small numbers of cases. Difficulty in availability of intravenous ibuprofen and indomethacin makes it difficult to do a randomized control trial in Nepal. Easy availability and affordable price of intravenous paracetamol favours its use for PDA closure in a developing country. Although there have been studies regarding the use of oral paracetamol for PDA closure with promising results, the oral route may not be feasible for administering drugs to infants of VLBW and ELBW because of frequent feed intolerance requiring nil by mouth status as well as their gut immaturity giving rise to an unpredictable intestinal absorption. Currently there is no published data in Nepal regarding the use of intravenous paracetamol for patent ductus arteriosus closure. More studies are needed to know the best route of administration, long-term consequences and side effects of using paracetamol as a treatment modality for closing PDA.

\section{Conflict of Interest: None}

\section{REFERENCES}

1. Wilson-Smith EM, Morton NS. Survey of i.v. paracetamol (acetaminophen) use in neonates and infants under 1 year of age by UK anesthetists. Pediatr Anesth. 2009;19(4):329-37. doi: 10.1111/j.1460-9592.2009.02947.x.

2. Fay FS, Kooke PH. Guinea pig ductus arteriosus, II: irreversible closure after birth. Am J Physiol.1972;222:841-9.

3. Yekta M, Yukurttutan S, Erdeve O, Uras N, Altug N, Oguz S, et al. Oral paracetamol versus oral ibuprofen in the management of PDA in preterm infants: a randomized control trial. J Pediatrics. 2014;164:510-4.

4. Koch J, Hensley G, Roy L, Brown S, Ramaciotti C, Rosenfeld CR. Prevalence of spontaneous closure of the ductus arteriosus in neonates at a birth weight of 1000 gram or less. Pediatrics. 2006 Apr 1;117(4):1113-21.

5. Hammerman C, Bin-Nun A, Markowitz E, Schimmel MS, Kaplan M. Ductal closure with paracetamol: a surprising new approach to patent ductus arteriosus treatment. Pediatrics. 2011;128:e1618-21.

6. Memisoglu A, Alp Ünkar Z, Cetiner N, Akalın F, Ozdemir H, Bilgen HS, Ozek E. Ductal closure with intravenous paracetamol: a new approach to patent ductus arteriosus treatment. J Matern Fetal Neonatal Med. 2015;1- 4.

7. Le J, Gales MA, Gales BJ. Acetaminophen for patent ductus arteriosus. Ann Pharmacother .2015. 49:241-246. doi:10.1177/1060028014557564

8. Xiao Y, Liu H, Hu R, You Q, Zeng M and Jiang X (2020) Efficacy and Safety of Paracetamol for Patent Ductus Arteriosus Closure in Preterm Infants: An Updated Systematic Review and MetaAnalysis. Front. Pediatr. 7:568. doi: 10.3389/fped.2019.005

9. Valerio E, Valente MR, Salvadori S, Frigo AC, Baraldi E, Lago P. Intravenous paracetamol for PDA closure in the preterm: a single-center experience. European Journal of Pediatrics.
2016;175:7:953-966.

10. Tofe I, Ruiz-Gonzalez MD, Canete MD, Pino A, Rueda RL, Parraga $\mathrm{MJ}$ and Perez-Navero JL. Efficacy of Paracetamol in Closure of Ductus Arteriosus in Infants under 32 weeks of gestation. Front. Pediatr 2018;6:25. doi: 10.3389/fped.2018.00025

11. Sunil B, Patel S, Girish N. IV Paracetamol for closure of patent ductus arteriosus in preterm neonates admitted to a tertiary care centre. Int J Contemp Pediatr 2018;5:294-8.

12. Guimaraes AF, Araujo FD, Meira ZM, Tonelli HA, Duarte GG, Ribeiro LC, et al. Acetaminophen in low doses for closure of the ductus arteriosus of the premature. Ann Pediatr Card 2019;12:97-102.

13. Dash SK, Kabra NS, Avasthi BS, Sharma SR, Padhi P, Ahmad $J$, et al. Enteral paracetamol or intravenous indomethacin for closure of patent ductus arteriosus in preterm neonates: A Randomized controlled trial. Indian Pediatr 2015;52:573-8.

14. El-Khuffash A, Jain A, Corcoran D, Shah PS, Hooper CW, Brown $\mathrm{N}$, et al. Efficacy of paracetamol on patent ductus arteriosus closure may be dose dependent: Evidence from human and murine studies. Pediatr Res 2014;76:238-44. 